\title{
THERAPEUTIC POTENTIAL OF MESENCHYMAL STEM CELL- DERIVED EXTRACELLULAR VESICLES IN REGENERATIVE ENDODONTICS
}

\author{
A. Ivica ${ }^{1}$, M. Zehnder ${ }^{1}$ and F.E. Weber ${ }^{2, *}$ \\ ${ }^{1}$ Preventive Dentistry, Periodontology and Cariology, Centre for Dental Medicine, University of Zurich, \\ Zurich, Switzerland \\ ${ }^{2}$ Oral Biotechnology and Bioengineering, Centre for Dental Medicine, University of Zurich, Zurich, \\ Switzerland
}

\begin{abstract}
Regenerative endodontic procedures are an alternative to conventional root-canal treatment and apexification. There are two different tissue engineering approaches that are currently followed, both aiming at the colonisation of the cleaned pulp space by pluripotent cells and subsequent pulp regeneration. Firstly, the transplantation of mesenchymal stem cells (MSCs), and secondly a cell-free strategy that relies on bioactive molecules to trigger the recruitment of the patient's own cells. The first approach is hampered by costs and regulatory issues. Despite great initial enthusiasm with a clinically used cell-free approach that relies on induced bleeding into the pulp space, results have been revealed to be rather unpredictable, and mere repair rather than regeneration of the pulp-dentin complex is what is typically achieved. Moreover, the extent of further root development is variable, and the concept is limited to immature teeth. This article discusses a third possible way of regenerative endodontics that involves the application of MSC-derived exosomes. These are extracellular vesicles that contain proteins, lipids, and nucleic acids, reflecting the secretome of MSCs. Based on the first in vitro and in vivo studies, exosomes appear to be a potent tool to improve pulp regeneration. This narrative review aims to investigate the therapeutic use of human MSCs or dental pulpderived exosomes in regenerative endodontics. Furthermore, the focus of this review is on targeting important questions that should be investigated in future in-vivo and clinical studies, such as the choice of scaffold material for exosome delivery into the pulp space.
\end{abstract}

Keywords: Regenerative endodontics, dental pulp, exosomes, extracellular vesicles, regeneration.

*Address for correspondence: Franz E. Weber, Schönleinstrasse 2, 8032 Zurich, Switzerland. Telephone number: +41 446343140 Email: franz.weber@zzm.uzh.ch

Copyright policy: This article is distributed in accordance with Creative Commons Attribution Licence (http://creativecommons.org/licenses/by-sa/4.0/).

\section{Introduction}

Regenerative medicine is a fast-growing field. Its concepts aim to replace or restore diseased cells, tissues, or organs, and to restore their functionality. Because oral diseases pose a significant public health problem, there is a continued search for better and more efficient treatments, including attempts to implement regenerative approaches. It was estimated that at least 3.58 billion people suffer from oral diseases worldwide (Kassebaum et al., 2017). The health of the tooth may be compromised due to infection, trauma, or some developmental abnormalities, which can lead to irreversible pulpitis or necrosis. Traditional endodontic treatments merely seek to clean and then seal the canal space with synthetic materials, and thus result in the repair of the non-infected tissues. However, these procedures fail to promote continued root development, leaving immature teeth susceptible to fractures and without internal vitality (Diogenes et al., 2016). Because an endodontically treated tooth does not contain a vital pulp, it cannot fight against caries and other attacks. Regenerative endodontics with the goal to regenerate lost pulp tissue was thus proposed as an alternative to conventional endodontic treatment for immature teeth (Hargreaves et al., 2008; Mao et al., 2012).

As a common concept, tissue engineering treatments utilise a combination of stem cells, growth factors, and scaffolds to induce functional tissue regeneration (Langer and Vacanti, 1993). One of the best-studied stem cell types in this context are mesenchymal stem cells (MSCs). They can be isolated from dental tissues, are widely available throughout 
all life stages and represent an important tool, not only for craniofacial regeneration, but also to treat a growing number of other conditions (Sharpe, 2016). Since dental tissues represent a particularly attractive source for stem cells because of their availability, dental MSCs have been extensively investigated. Moreover, there are stem cell banks worldwide, offering MSCs to be transplanted and used in clinical and commercial applications (Codispoti et al., 2018). The formation of pulp-like tissue after the transplantation of dental pulp cells into an empty tooth was first shown in dogs and later in humans (Iohara et al., 2011; Nakashima et al., 2017). Despite these positive results, however, there are many technical problems with the direct application of MSCs. At the current stage of the technology, the cost of such a therapy would be forbiddingly high to save one tooth and, even more importantly, there may be a risk of contamination and immunorejection (Mao et al., 2012). Therefore, clinical protocols for regenerative endodontics are not and will probably never be based on cell transplantation, but rely on cell homing (Galler et al., 2016). The latter is defined as the recruitment of a patient's own stem cells to a damaged part of a tissue induced by chemotaxis (Kim et al., 2010). The main limitation of this strategy is however the predictability of the number of the recruited cells. Moreover, as discussed below, the current concept does not yield predictable results and can lead to blood- and material-induced tooth discoloration (Chrepa et al., 2020; Kahler et al., 2014). The use of recombinant growth factors may induce non-desirable side effects, because of their pleiotropic effects on metabolism.

The paradigm shift from cell-based approaches to possibly the concepts discussed in this article was spurred by growing evidence that, while current cellfree tissue engineering approaches in endodontics do not yield the expected results, there may be an intermediate route in between cell-based and cell-free concepts. This idea is based on the historic evidence that conditioned medium of MSCs could have therapeutic effects on ischemic heart disease (Gnecchi et al., 2006). That phenomenon started the recent research boom in exosomes that are found in the conditioned medium together with other paracrine mediators. Since then, there has been a tremendous interest in use of exosomes instead of MSCs for the purpose of regenerative medicine (Phinney and Pittenger, 2017). In dentistry, however, where such concepts may find earlier clinical application than in other fields dealing with more systemically important organs, research is still limited to laboratory and animal investigations. This review therefore focuses on the therapeutic potential of MSC-derived exosomes in regenerative endodontics and aims at giving an overview of the recent developments in this field.

\section{MSCs and their therapeutical effects}

Stem cells are defined as immature, primitive, undifferentiated cells that have the ability to differentiate into multiple lineages (Miyajima et al., 2014). Eventually, they can give rise to a progenitor cell that differs slightly from the initial cell and that will differentiate into a more mature cell of the respective tissue. This is a process important for tissue homeostasis. The older cells are removed, and the tissue is constantly being regenerated from stem cells (Clevers et al., 2014). Likewise, a stem cell may also divide into another stem cell or self-renew, which is a tool to protect the stem cell pool from exhaustion.

The term MSCs refers to cells isolated from stroma, the connective tissue that surrounds other tissues and organs. Because these cells did not show any teratogenic potential in animal models and can easily be cultured from different human tissues, such as bone marrow, dental pulp and fat, they have been frequently used and investigated (Pittenger et al., 1999). MSCs may support regeneration in several ways. They release cytokines and growth factors to orchestrate cell migration, proliferation, angiogenesis, immune system recognition and the expansion of $B$ and T cells (Dexter et al., 1990). The first time the allogeneic MSCs were used was to treat patients with osteogenesis imperfecta. The improvements in bone structure and function obtained were reported (Horwitz et al., 1999). Since then, MSCs have been used in a large number of different animal models and randomised clinical trials, including treatment of acute myocardial infarction, ischaemic stroke, acute kidney failure and Crohn's disease as well as steroidrefractory acute graft-versus-host disease (acute GvHD), which arises as a side effect of allogeneic hematopoietic stem cell transplantation therapies (Giebel et al., 2017).

In many aspects, MSC therapy showed numerous advantages over conventional treatments. Adding MSCs into bone tissue engineering seems to be a key improvement, since they promote rapid tissue remodelling and trigger vascular differentiation, which is especially important in a tissue with a limited vascular capacity (Khojasteh et al., 2017). Moreover, MSC-based therapy significantly improves wound healing and angiogenesis in skin defects (Pelizzo et al., 2018). Because of their immunomodulatory capacity, MSCs are also used for liver regeneration in acute liver failure (Shi et al., 2017). However, this MSCbased therapy may also have serious side effects. Upon studying the distribution of intravenously injected MSCs it was reported that, because of their large size, MSCs are rapidly trapped within the pulmonary capillaries, causing pulmonary and haemodynamic problems (Schrepfer et al., 2007). In the literature there are several studies suggesting that the application of MSCs may lead to tumourigenesis, 
post transplantation infection, secondary injury, and congenital abnormalities (Dlouhy et al., 2014; Goldstein et al., 2010; Rebelatto et al., 2008; Hovatta, 2011).

\section{Extracellular vesicles}

Cells secrete different types of membrane vesicles, known as extracellular vesicles. Various names have been used to refer to these vesicles (van Niel et al., 2018). Depending on their origin, they can be broadly divided into exosomes and microvesicles or ectosomes. Exosomes are of endocytic origin and secreted by fusion of these vesicles with the cell membrane. Microvesicles form from the surface of the plasma membrane by outward budding (Abels and Breakefield, 2016). Despite the difference in their origin, the mechanism responsible for biogenesis of both types of vesicles is the same (van Niel et al., 2018). Further, extracellular vesicles can be subdivided according to their size into apoptotic bodies, microparticles and exosomes. The latter range from $40 \mathrm{~nm}$ to $150 \mathrm{~nm}$ in diameter. Some scientists prefer the term exosome as a generic alternative instead of extracellular vesicle. To solve this nomenclature disagreement, the International Society for Extracellular Vesicles suggested that the term extracellular vesicles be used (Witwer and Théry, 2019).

Extracellular vesicles are encapsulated small portions of the parent cell, which are secreted into extracellular fluid or culture media (Koritzinsky et al., 2017). For a long time, it was believed that these vesicles were just cellular waste and they were considered insignificant. However, their lipid bilayer contains a complex cargo of proteins, lipids, and nucleic acids, which mirrors their cell source and exert similar effects to the cells they derived from (Gurunathan et al., 2019). Extensive research has been carried out to characterise the cargo of extracellular vesicles. The content of vesicles is highly heterogenous and depends on the cell type and the physiologic conditions (Abels and Breakefield, 2016). Proteomics, a large-scale study of proteins and their functions (Kupcova Skalnikova, 2013) of exosomes revealed common proteins in extracellular vesicles like tetraspanins (CD9, CD63, CD81, and CD82), Rab GTPases, flotillin, Alix, TSG101, heat shock proteins (Hsc70, Hsp90), antigen-presentation proteins (MHC-I and MCH-II) and receptors (tumour necrosis factor receptor 1) (Qing et al., 2018; Deng et al., 2018). Proteins that are associated with basic cellular functions, such as membrane trafficking, cell junction, the cytoskeleton, and structure in general, are present in all extracellular vesicles. In addition, the proteome of MSC-derived extracellular vesicles often includes enzymes and signalling molecules like cytokines, interleukins, chemokines, and growth factors (Deng et al., 2018). Therapeutic efficacy could be mediated by exchanging cell signalling proteins such as TNF- $\alpha$, TGF- $\beta$, Wnt5, $\beta$-catenin and etc. from the extracellular vesicles to their surroundings. Thus, MSC-derived exosomes could potentially help tissue regeneration by providing catalytically active enzymes or growth factors (Anderson et al., 2016). Extracellular vesicles are rich in miRNA, small single-stranded non-coding RNA molecules. Transfer of miRNA through exosomes has been widely studied as a possible mechanism of intercellular communication. The concept that miRNA from the exosomes can be delivered to other cells, resulting in direct modulation of their mRNA targets, has become one of the most attractive hypotheses in the field (Tkach and Théry, 2016). It was demonstrated in vivo that exosomes from Epstein-Barr virus-infected cells transferred the virus to noninfected cells (Pegtel et al., 2010).

Extracellular vesicles act in both physiological and pathological processes. They are important for cell communication and the transmission of information to further locations (He et al., 2018). They may enter into a cell via more than one route. All extracellular vesicles carry surface molecules to be recognised by recipient cells (Tkach and Théry, 2016). They are usually taken up by endocytosis/ phagocytosis (Montecalvo et al., 2012). The recipient cell may also fuse directly with the membrane of a vesicle, or the uptake occurs by receptor-ligand interactions (Mulcahy et al., 2014). Thus, extracellular vesicles represent a key concept in mediating changes in cellular behaviour by affecting cells in a paracrine or an endocrine manner, which makes them useful therapeutically (Zhang et al., 2019). Because of their rapid uptake, it is more likely that their primary function is to exchange information with neighbouring cells and not to interfere with distant cellular targets (Smyth et al., 2015). Unlike MSCs, extracellular vesicles cannot renew themselves and thus lack endogenous potential for tumourigenesis (Giebel et al., 2017).

\section{Exosomes and their potential therapeutic effects}

It was demonstrated that MSCs have immunemodulating properties (Bartholomew et al., 2002). Since this does not require cell-cell interaction, it has been suggested that the anti-proliferation activity of MSCs on T-cells could be due to the secretion of modulating factors by these cells (Di Nicola et al., 2002). This led to the hypothesis that tissue repair may be orchestrated through paracrine factors of MSCs and stimulation of host cells, and not necessarily by cell replacement (Caplan and Dennis, 2006). Moreover, experiments on cardioprotective effects of conditioned media suggested that vesicular structures, identified as exosomes, have cardioprotective properties (Lai et al., 2010). These active components in the conditioned medium of 
human MSCs were within the 100 to $200 \mathrm{~nm}$ range (Timmers et al., 2007). This gave a new perspective into intercellular mediation of tissue repair.

A major advantage of exosomes is that they represent a cell-free therapy. Moreover, unlike other nanoparticles, exosomes show the rapid clearance and the absence of unwanted accumulation in liver, which could explain their favourable toxicity profile (Fu et al., 2019; Smyth et al., 2015). Most importantly, because they do not express HLA (human leukocyte antigen) class II, exosomes are hypoimmunogenic (Phinney and Pittenger, 2017). Most experimental evidence suggests that exosomes harvested from MSCs show a very similar biological activity to the MSCs proper (Nakamura et al., 2015; Timmers et al., 2007; Zhang et al., 2015). Due to their great biocompatibility exosomes have attracted wide attention in the medical community (Kalimuthu et al., 2018).

There has been a fundamental change of focus from using MSCs in a therapeutic manner to the mere application of exposomes, which is reflected in the number of more than 180 clinical trials using exosomes as reported in www.clinicaltrials.gov in August 2020 (Web ref. 1). Some clinical trials using exosomes from human specimens are completed and results showed that exosomes were well-tolerated. Depending on the cell source, exosomes can promote or suppress inflammatory activity or boost antitumour response (Chen et al., 2019).

The harvesting of exosomes is usually performed using centrifugation steps on a size-based isolation strategy. This is the most widely adopted method, but it is time consuming and works only with large sample volumes (He et al., 2018). There are also other methods for exosome isolation, such as ultrafiltration, chromatography, polymer-based precipitation, immunoaffinity capture or antibody-coupled magnetic beads (Gurunathan et al., 2019). Exosomes may be isolated from human plasma, saline, urine, blood, semen or culture medium.

Extracellular vesicles are less complicated to handle than cells. To attain routine clinical usage, however, a crucial point is to identify optimal isolation and storage conditions, as the use of fresh extracellular vesicles is not practical. Recently, Ibsen et al. established an alternating current electro kinetic microarray chip device for rapid isolation and recovery of exosomes from human plasma within 15 min (Ibsen et al., 2017). Interestingly, there is also a novel approach named "NANOBIOME" that offers the biobanking of exosomes (Codispoti et al., 2018). MSCs have the capacity to mass produce exosomes. Following this route, high-quality exosomes may be collected, processed, and preserved for clinical application. For their preservation and storage, there are options like freezing or lyophilisation. Interestingly, the freezing cycles do not negatively affect the stability of exosomes, neither in terms of structure nor composition (Codispoti et al., 2018). Freezing at $-80{ }^{\circ} \mathrm{C}$ in trehalose with or without protease inhibitors seems to be a convenient way of storage (Le Saux et al., 2020). Moreover, freezedrying allows satisfactory shipping conditions and long-term storage, avoiding any risk of thawing or degradation (Frank et al., 2018; Le Saux et al., 2020). Such techniques are gradually advancing the routine manufacture of exosomes and their clinical distribution. Because of their small size, extracellular vesicles may be sterilised through filtration (Giebel et al., 2017).

\section{Extracellular vesicles derived from oral cavity MSCs}

Dental tissues represent a particularly attractive source of MSCs, wherefrom exosomes may be extracted. Because teeth are often discarded in the clinic as medical waste, their examination does not necessarily require ethical approval (Egusa et al., 2012). These tissues consist of heterogeneous cells, as they, beside MSCs, include progenitor cells, fibroblasts, neural cells, endothelial cells and immune system cells. Besides dental pulp stem cells (DPSC) and stem cells from exfoliated deciduous tooth (SHED), MSCs are also present in the periodontal ligament, apical papilla, gingiva, tooth germ and bone marrow. Further work is required to effectively classify the properties of exosomes derived from those specific MSCs to better understand which source may be used for regenerative purposes. Because exosomes could be relatively easily harvested from a patient's wisdom teeth or from deciduous teeth, these cell sources have a great potential to be tested in clinical trials.

Exosomes derived from gingival MSCs combined with poly(lactide) scaffold promoted bone regeneration in an animal model for the study of calvarial bone repair (Diomede et al., 2018b). Moreover, an extensive vascular network was observed, suggesting an osseointegration process (Trubiani et al., 2019). Extracellular vesicles released from periodontal ligament stem cells showed similar results (Diomede et al., 2018a). It may be assumed that exosomes boost the osteoinductive activity through the activation of endogenous bone marrow MSCs in the bone defect.

\section{Regenerative endodontics now}

Regenerative endodontics has its roots in the work of Nygaard-Østby in the 1960s (Nygaard-Østby, 1961). In 2001, Iwaya and Ikawa reopened the field by showing a case report on the continued root growth of an immature permanent tooth with apical periodontitis and a sinus tract (Iwaya et al., 2001). The tooth, however, had a dens evaginatus, and its endodontic condition was hardly that of a tooth affected by caries or trauma. Despite a great deal of enthusiasm at the beginning, which was partly based on mis-interpretation of such individual case reports 
and the disregard of pulp tissue possible conditions in necrotic teeth with caries versus trauma, there are many challenges that must be overcome in order to achieve better clinical results. At the core of these problems is the fact that in the absence of a vital pulp stump, there is little pulpal regeneration (Edanami et al., 2020), and the pulp space repairs with periodontal tissues (Lui et al., 2020; Nygaard-Ostby and Hjortdal, 1971).

One clinical pilot study and several animal studies supported the potential applicability of cell transplantation for pulp regeneration therapy (Iohara et al., 2011; Nakashima et al., 2017; Xuan et al., 2018). However, there are many regulatory barriers, such as a risk of contamination and immunorejection (Mao et al., 2012). It is noteworthy that cell transplantation requires sophisticated materials and techniques. To circumvent all these negative aspects, other possibilities should be further explored and optimised. Mao and his group were the first to demonstrate that, in an animal model with human teeth, the regeneration of dental pulp was achievable by the attraction of host endogenous cells and without cell transplantation, i.e. cell homing (Kim et al., 2010). However, they used a mix of morphogens that was applied into the cleaned pulp space to investigate their research question. Clinically, the cell-free concept that has been accepted both by the American Association of Endodontists (AAE) and the European Society of Endodontology (ESE) for the treatment of immature teeth with pulp necrosis (Galler et al., 2016), however, merely relies on controlled bleeding into the formerly cleaned pulp space and blot clot formation (Nygaard Ostby, 1961; Trope, 2010). It may be surmised that application of tissue factors has not been followed by any dental company because of regulatory impasses. The ESE suggested the protocol shown in Fig. 1 that a
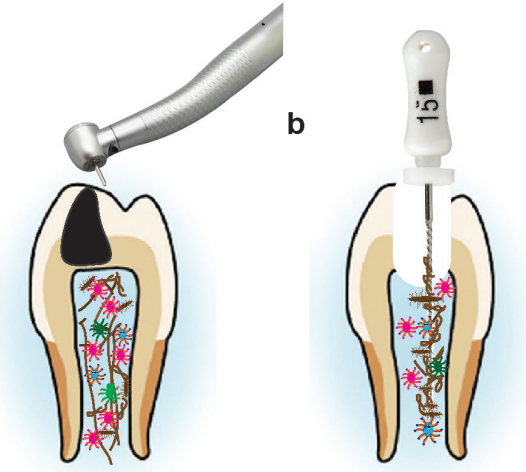

e

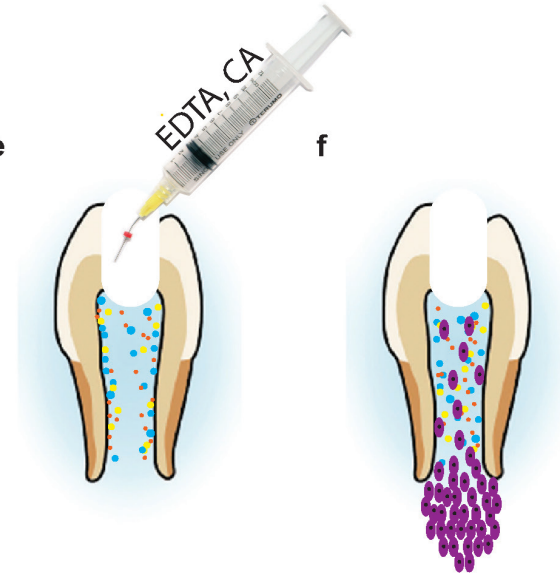

C

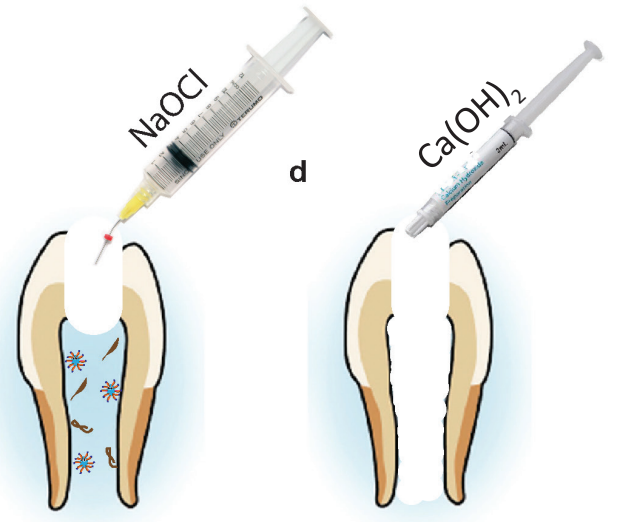

g

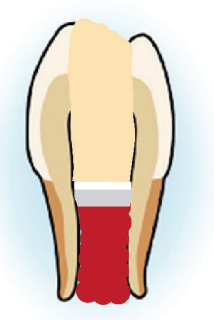

h

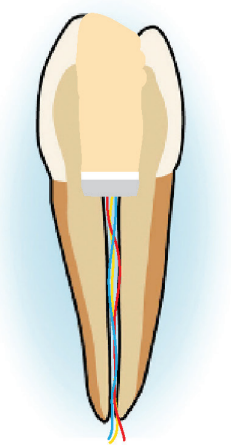

Fig. 1. Current protocol recommended by ESE based on cell homing strategy. (a) The first step is to open a pulp chamber. (b) This is followed by pulp extirpation and (c) disinfection. (d) Calcium hydroxide dressing is used as intracanal medicament between two appointments. (e) Next step is dentine conditioning to release growth factors that are (f) embedded in dentine to recruit stem cells. Afterwards bleeding is induced so that blood clot may serve as a scaffold. MTA plug ensuring a thickness of 2-3 $\mathrm{mm}$ should be placed on the top of the blood clot underneath cemento-enamel junction. A flowable, light-curable glass-ionomer is applied on top of it. (g) The tooth is sealed with adhesive restoration. (h) Pulp regeneration with re-continued root development. 
includes access cavity preparation and removal of necrotic pulp tissue followed by disinfection. Sodium hypochlorite $(\mathrm{NaOCl})$ is the first choice for disinfection (Martin et al., 2014). Although there is no consensus on the application of calcium hydroxide as a medicament in-between two appointments, several studies have shown a positive effect of this medicament on stem cell survival (Ruparel et al., 2012). Dentin conditioning with some chelating agent such as ethylenediaminetetraacetic acid (EDTA) or citric acid liberates growth factors from dentin (Galler et al., 2015). This helps to recruit stem cells and to differentiate them into cells that resemble those found in normal pulps (Ivica et al., 2019). Bleeding induced by over-instrumenting is used to form a blood clot. However, blood clot formation is not always achievable and it may lead to tooth discoloration by the diffusion of haemoglobin into dentinal tubules (Saoud et al., 2014). A hydraulic calcium silicate cement (e.g. MTA or tricalcium silicate cement) is placed coronally to this clot, which is then followed by the final restoration. Parameters that define success of such a treatment are the healing of a pre-existing periapical lesion, increase of root thickness and length, apical closure, and positive response to sensitivity testing (Kahler et al., 2017).

The histological assessment of human teeth, treated by the regenerative approaches that are currently allowed, mostly showed tissue repair or a combination of repair and regeneration. In some cases, replacement of the dentin-pulp complex by periodontal supporting tissues, including bone and cementum, was observed (Digka et al., 2020; Lui et al., 2020). Between researchers, there is no consensus on the types of tissues that are generated in the pulp space following regenerative therapy. However, for clinicians it seems to be unimportant if there is repair or regeneration as long as the patient is asymptomatic, a tooth responds positively to vitality testing, and there is lengthening and thickening of the dentine walls of immature teeth (Galler et al., 2016). From a research perspective, however, the final goal of the regeneration treatment is to re-establish the original form and function of the damaged structures, in our case, the pulp-dentin complex. This would result in a deposition of tissues that are at the histological level similar to non-damaged dentine and with wellknown architecture of the pulp. In addition, there are some patient-related outcomes that need to be added into the equation, such as crown discoloration, tooth functionality, pain, the number of dental appointments and patient satisfaction (Diogenes et al., 2016). As an example, a meta-analysis showed that tooth discoloration was reported in $40 \%$ of the cases treated by current regenerative techniques, which is a severe problem since front teeth are the most common teeth in need of such treatment (Torabinejad et al., 2017).

In summary, it may be stated that while there is a will to use tissue engineering concepts in clinical endodontics, the results obtained with what is currently available to practitioners must be improved upon. The predictability of these treatment outcomes and other unwanted consequences are due to a shortage of recruited autologous stem cells in necrotic root canals and the lack of a suitable scaffold to replace the blood clot (Song et al., 2017).

\section{Potential therapeutic effects of MSC-derived extracellular vesicles in regenerative endodontics and beyond}

Thanks to its accessibility, the dental pulp is of particular interest and displays great advantages compared to other sources of MSCs. Therefore, exosomes derived from dental pulp cells have also been studied extensively in the past few years. It would appear that they can promote healing in neurological and vascular diseases, osteoarthritic disorders, liver and lung regeneration and many other conditions (Kichenbrand et al., 2019). The use of dental pulp-derived exosomes for applications other than regenerative endodontics was not the focus of the current review and should be discussed in future communications. In terms of pulp regeneration, most of the studies investigating the role of exosomes on regenerative properties used DPSC as a source of exosomes (Table 1). Since fibroblasts and endothelial cells contribute to dentine repair and pulp healing, it may be useful to harvest exosomes from the whole dental pulp, e.g. the mixture of cells and not only DPSC (Ivica et al., 2020; Xian et al., 2018). Odontoblasts secrete exosomes with anti-apoptotic features, which may be particularly important during inflammation (Wang et al., 2019). However, whether exosomes from different cell types contribute to the better microenvironment for triggering pulp regeneration or not awaits further clarification. It may be so that since exosomes carry the functions of their maternal cells, different exosomes may be necessary for specific applications within dentistry. A further question is whether there are differences between the exosomes secreted from young and adult patients (Iezzi et al., 2019).

Huang et al. demonstrated the beneficial effect of exosomes isolated from dental pulp stem DPSC on odontoblastic differentiation of naïve cells (Huang et al., 2016). It was suggested that exosomes promoted the odontogenic differentiation by the transfer of microRNAs. Moreover, when the cells were cultured with odontogenic medium and afterwards the exosomes were extracted, the effect was even stronger compared to the normal culturing conditions.

To clarify the underlying mechanism, microRNA sequencing was conducted (Hu et al., 2019). The analysis showed that microRNA levels in exosomes extracted from the cells cultured in odontogenic medium were significantly changed when compared to those in regular medium. Furthermore, these authors demonstrated that exosomes promote odontogenic differentiation by 
Table 1. Dental pulp derived exosomes in pulp regeneration and repair.

\begin{tabular}{|c|c|c|c|}
\hline Origin of exosomes & Type of study & Observation & Reference \\
\hline DPSC & $\begin{array}{l}\text { in vivo - induced acute } \\
\text { inflammation in mice }\end{array}$ & Exosomes show strong anti-inflammatory effects & $\begin{array}{l}\text { Pivoraite } \\
\text { et al., } 2015\end{array}$ \\
\hline DPSC & $\begin{array}{l}\text { in vivo - the root slices } \\
\text { implanted into the back } \\
\text { of mice }\end{array}$ & $\begin{array}{l}\text { Exosomes promote differentiation of stem cells; exosomes } \\
\text { isolated under odontogenic conditions have stronger effect }\end{array}$ & $\begin{array}{l}\text { Huang } \\
\text { et al., } 2016\end{array}$ \\
\hline $\begin{array}{l}\text { Epithelium and } \\
\text { mesenchyme cells } \\
\text { of developing tooth }\end{array}$ & in vivo in rats & $\begin{array}{l}\text { Exosomes travel between epithelium and mesenchyme during } \\
\text { tooth development leading to reciprocal cell differentiation and } \\
\text { matrix synthesis }\end{array}$ & $\begin{array}{l}\text { Jiang } \\
\text { et al., } 2017\end{array}$ \\
\hline Dental pulp & in vitro & $\begin{array}{l}\text { Exosomes promoted endothelial cell proliferation, paracrine } \\
\text { angiogenic factor expression and tube formation }\end{array}$ & $\begin{array}{l}\text { Xian } \\
\text { et al., } 2018 \\
\end{array}$ \\
\hline DPSC & in vitro & $\begin{array}{l}\text { MicroRNAs significantly changed in odontogenic exosomes } \\
\text { compared to normal conditions; exosomes trigger odontogenic } \\
\text { differentiation via TGF } \beta 1 / \text { Smads signalling pathway }\end{array}$ & $\begin{array}{l}\mathrm{Hu} \\
\text { et al., } 2019\end{array}$ \\
\hline $\begin{array}{l}\text { Odontoblasts and } \\
\text { odontoblast-like } \\
\text { cells }\end{array}$ & in vitro & $\begin{array}{l}\text { Exosomes reduce apoptosis in neighbouring cells; increased } \\
\text { levels of CD63 (exosome marker) in the region affected by caries }\end{array}$ & $\begin{array}{l}\text { Wang } \\
\text { et al., } 2019\end{array}$ \\
\hline Dental pulp & in vitro & $\begin{array}{l}\text { Exosomes trigger migration and proliferation of BMMSCs; fibrin } \\
\text { gel and exosomes have synergistic effect on stem cell attraction }\end{array}$ & $\begin{array}{c}\text { Ivica } \\
\text { et al., } 2020\end{array}$ \\
\hline DPSC & $\begin{array}{l}\text { in vivo - rat } \\
\text { pulpotomy model }\end{array}$ & $\begin{array}{l}\text { Exosomes loaded into biodegradable polymeric scaffold and } \\
\text { used as pulp capping material enhance tertiary dentineogenesis } \\
\text { and dentine bridge formation }\end{array}$ & $\begin{array}{l}\text { Swanson } \\
\text { et al., } 2020\end{array}$ \\
\hline SCAP & $\begin{array}{l}\text { in vivo - the root } \\
\text { fragments implanted } \\
\text { subcutaneously into } \\
\text { immunodeficient mice }\end{array}$ & $\begin{array}{c}\text { Exosomes are endocytosed by BMMSCs and orchestrate their } \\
\text { specific dentineogenesis }\end{array}$ & $\begin{array}{l}\text { Zhang } \\
\text { et al., } 2020\end{array}$ \\
\hline DPSC & in vitro & $\begin{array}{l}\text { Fibrin gel loaded with exosomes supports neovascularisation } \\
\text { and collagen I, III, IV deposition; fibrin preserved the activity of } \\
\text { exosomes for at least } 7 \mathrm{~d}\end{array}$ & $\begin{array}{l}\text { Zhang } \\
\text { et al., } 2020\end{array}$ \\
\hline
\end{tabular}

the transforming growth factor- $\beta$ (TGF- $\beta$ ) signalling pathway by downregulating the inhibitory molecule LTBP1. TGF- $\beta$ signalling is well known to play important roles in odontogenic differentiation and tooth morphogenesis (He et al., 2014). Moreover, exosomes derived from human DPSC have strong anti-inflammatory effects (Pivoraitė et al., 2015).

It is well known that tooth development requires interaction of cells in different tissues. In mice it was shown that during tooth formation, exosomes are secreted by both the epithelium and mesenchyme (Jiang et al., 2017). Those exosomes reciprocally trigger cell differentiation and matrix secretion. Epithelium exosomes are taken in by mesenchymal cells that afterwards produce dentine sialoprotein and start mineralisation. At the same time, mesenchymal exosomes induced epithelium cells to produce ameloblastin and amelogenenin.

Wang et al. established an in vitro model to study the possible role of exosomes in dental caries (Wang et al., 2019). In caries progression, odontoblasts show different levels of inflammation. The odontoblasts that are closer to the site of injury exhibited more severe signs of inflammation. At the same time, those odontoblasts secreted an increased number of exosomes, comparing to the mildly injured counterparts along the periphery of the caries lesion. Interestingly, exosomes helped to block apoptosis.

As discussed above, in regenerative endodontic procedures that are based on a cell homing strategy, the main problem is to recruit the patient's endogenous mesenchymal stem cells (Kling et al., 1986). Human bone marrow-derived mesenchymal stem cells are mobilised into the circulation and represent an important source of stem cells for pulp regeneration. It was shown that exosomes from human pulp attract bone marrow-derived mesenchymal stem cells in vitro (Ivica et al., 2020). Moreover, in the same study, it was reported that stem cell proliferation was strongly affected by exosomes. Differentiation towards odontoblasts was also detected in BMMSCs after they were endocytosed (Zhuang et al., 2020).

\section{Delivery and matrix systems for pulpal regeneration in conjunction with exosomes}

In order to use exosomes as a therapeutic tool, an appropriate delivery system which allows the direct application to the injury site is required. Drug delivery strategies are a tremendous challenge in tissue engineering (Jain et al., 1998). To investigate how the exosomes may be applied clinically in regenerative endodontics, they were combined with a collagen membrane and used to fill the roots of human teeth before being subcutaneously implanted in rats (Huang et al., 2016). Results showed that exosomes could enhance the regeneration of pulp-like tissue. An increase in the expression levels of growth factors TGF- $\beta 1$, BMP-2, RUNX2 and PDGF, markers for odontogenic differentiations, was observed in newly formed tissue in the groups where exosomes were used. Moreover, the results suggest that exosomes from dental pulp cells trigger angiogenesis, 
which is a critical step for the regeneration of the dentine-pulp complex (Xian et al., 2018). The level of vascular endothelial cell growth factor A (VEGF-A), the key growth factor that regulates angiogenesis, were increased when exosomes were used. Moreover, p38 MAPK signalling inhibition driven by exosomes enhance tube formation and stimulate endothelial cell angiogenesis. Similar results were seen when conditioned medium from human dental pulp stem cell was applied (Bronckaers et al., 2013). Fibrin-based scaffolds showed some advantage over other scaffolds used in the field of regenerative endodontics (Galler et al., 2018). When tested for use as delivery system for exosomes, results showed a synergistic effect of fibrin and the dental pulp-derived exosomes on stem cell attraction (Ivica et al., 2020). In another study, fibrin gel loaded with exosomes provoked vascularlike structure formation in less than $7 \mathrm{~d}$ (Zhang et al., 2020). Importantly, fibrin gels are commercially available clinically approved biomaterials and appear to be suitable delivery vehicles for exosomes in pulp regenerative procedures. However, additional preclinical and clinical studies are needed, especially related to their thrombin/fibrinogen composition and other physicochemical features relating to a controllable application in the root canal system (Hertig et al., 2017).

A recent study showed that controlled release of human DPSC exosomes from poly lactic-co-glycolic acid (PLGA)-based biodegradable scaffolds may be useful in pulp capping therapy (Swanson et al., 2020). Exosomes stimulated tertiary dentineogenesis and dentin bridge formation by promoting stem cell migration, odontogenic differentiation and mineralisation.

\section{Conclusions and future perspectives}

Because there are currently many challenges in regenerative endodontic treatment, a search for alternative clinically applicable strategies is indicated. MSCs have been used in different studies. Evidence has been provided that their therapeutic activities is mediated by their extracellular vesicles. In this context, exosomes are considered as potential therapeutic tools to avoid problems that are inherent to the use or application of whole stem cells. Moreover, along with tissue-engineering techniques, exosomal modification strategies are promising for the development of improved clinical therapies. Exosomes could be used as biomimetic tools to induce migration, proliferation and odontoblastspecific differentiation of stem cells in regenerative endodontic treatments (Table 1). Most of the current evidence for the use of exosomes in pulp regeneration come from in vitro or animal in vivo studies. Based on these studies, it is possible that the exosomes may have a positive effect on differentiation of naïve cells, their migration, proliferation and angiogenesis (Fig. 2). It seems like the exosomes derived from DPSC may be as good, if not better than using MSCs to regenerate a pulp. It was shown that transplantation of MSCs into injured tooth could regenerate dental pulp with odontoblasts at the periphery, histologically very similar to normal pulp tissue of a human tooth (Xuan et al., 2018). Because exosomes mimic the effects of MSCs, it is to be expected that they will trigger the regeneration and new tissue formation in the same way that MSCs do and, at the same time, by using exosomes technical problems that MSCs bring can be a

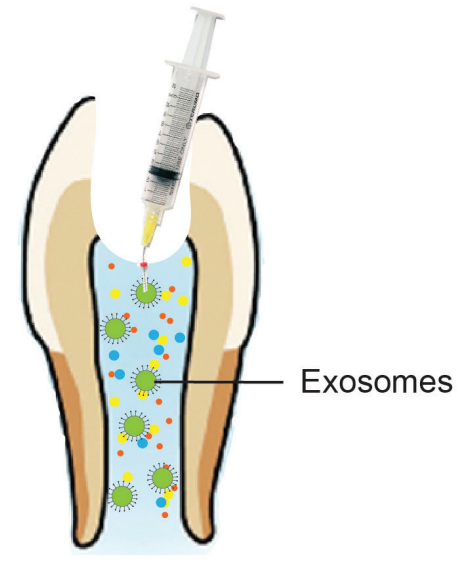

b

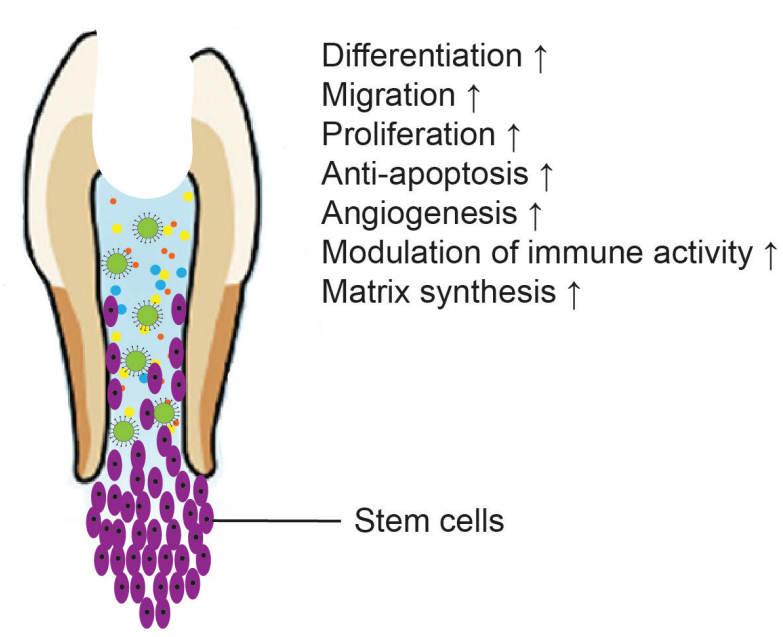

Reported effects of exosomes:

Differentiation

Migration $\uparrow$

Proliferation $\uparrow$

Anti-apoptosis $\uparrow$

Angiogenesis $\uparrow$

Modulation of immune activity $\uparrow$

Matrix synthesis $\uparrow$
Fig. 2. Schematic representation of using exosomes in pulp tissue regeneration. Firstly, a tooth is prepared as was explained in Fig. 1a-e. (a) Once a pulp chamber is cleaned and conditioned, MSC-derived exosomes are injected. (b) Exosomes could be used to promote the recruitment of patient's cells, differentiation and proliferation of naïve cells as well as anti-apoptosis and angiogenesis. 
avoided. Further clinical studies are needed to make a step forward in the application of this modifications in regenerative endodontics. To approach clinical use, this promising therapeutic strategy for regenerative endodontics has to prove its efficacy in clinical trials, and its effectiveness in everyday clinical use (Haynes, 1999). Moreover, an ideal vehicle for exosome delivery and scaffold formation in the pulp space needs to be identified. In that context, fibrin gels hold the greatest promise.

\section{References}

Abels ER, Breakefield XO (2016) Introduction to extracellular vesicles: biogenesis, RNA cargo selection, content, release, and uptake. Cell Mol Neurobiol 36: 301-312.

Anderson JD, Johansson HJ, Graham CS, Vesterlund M, Pham MT, Bramlett CS, Montgomery EN, Mellema MS, Bardini RL, Contreras Z, Hoon M, Bauer G, Fink KD, Fury B, Hendrix KJ, Chedin F, El-Andaloussi S, Hwang B, Mulligan MS, Lehtiö J, Nolta JA (2016) Comprehensive proteomic analysis of mesenchymal stem cell exosomes reveals modulation of angiogenesis via nuclear factor-kappaB signaling. Stem Cells 34: 601-613.

Bartholomew A, Sturgeon C, Siatskas M, Ferrer K, McIntosh K, Patil S, Hardy W, Devine S, Ucker D, Deans R, Moseley A, Hoffman R (2002) Mesenchymal stem cells suppress lymphocyte proliferation in vitro and prolong skin graft survival in vivo. Exp Hematol 30: $42-48$.

Bronckaers A, Hilkens P, Fanton Y, Struys T, Gervois P, Politis C, Martens W, Lambrichts I (2013) Angiogenic properties of human dental pulp stem cells. PLoS One 8: e71104. DOI: 10.1371/journal. pone.0071104.

Caplan AI, Dennis JE (2006) Mesenchymal stem cells as trophic mediators. J Cell Biochem 98: 10761084.

Chen YS, Lin EY, Chiou TW, Harn HJ (2019) Exosomes in clinical trial and their production in compliance with good manufacturing practice. Ci Ji Yi Xue Za Zhi 32: 113-120.

Chrepa V, Joon R, Austah O, Diogenes A, Hargreaves KM, Ezeldeen M, Ruparel NB (2020) Clinical outcomes of immature teeth treated with regenerative endodontic procedures - a San Antonio study. J Endod 46: 1074-1084.

Clevers H, Loh KM, Nusse R (2014) Stem cell signaling. An integral program for tissue renewal and regeneration: Wnt signaling and stem cell control. Science 346: 1248012. DOI: 10.1126/science.1248012.

Codispoti B, Marrelli M, Paduano F, Tatullo M (2018) NANOmetric BIO-banked MSC-derived exosome (NANOBIOME) as a novel approach to regenerative medicine. J Clin Med 7: 357. DOI: 10.3390/jcm7100357.

Deng H, Sun C, Sun Y, Li H, Yang L, Wu D, Gao Q, Jiang X (2018) Lipid, protein, and microRNA composition within mesenchymal stem cell-derived exosomes. Cell Reprogram 20: 178-186.

Dexter TM, Heyworth CM, Spooncer E, Ponting IL (1990) The role of growth factors in self-renewal and differentiation of haemopoietic stem cells. Philos Trans R Soc Lond B Biol Sci 327: 85-98.

Di Nicola M, Carlo-Stella C, Magni M, Milanesi M, Longoni PD, Matteucci P, Grisanti S, Gianni AM (2002) Human bone marrow stromal cells suppress T-lymphocyte proliferation induced by cellular or nonspecific mitogenic stimuli. Blood 99: 3838-3843.

Digka A, Sakka D, Lyroudia K (2020) Histological assessment of human regenerative endodontic procedures (REP) of immature permanent teeth with necrotic pulp/apical periodontitis: a systematic review. Aust Endod J 46: 140-153.

Diogenes A, Ruparel NB, Shiloah Y, Hargreaves KM (2016) Regenerative endodontics: a way forward. J Am Dent Assoc 147: 372-380.

Diomede F, D' Aurora M, Gugliandolo A, Merciaro I, Ettorre V, Bramanti A, Piattelli A, Gatta V, Mazzon E, Fontana A, Trubiani O (2018a) A novel role in skeletal segment regeneration of extracellular vesicles released from periodontal-ligament stem cells. Int J Nanomedicine 13: 3805-3825.

Diomede F, Gugliandolo A, Cardelli P, Merciaro I, Ettorre V, Traini T, Bedini R, Scionti D, Bramanti A, Nanci A, Caputi S, Fontana A, Mazzon E, Trubiani O (2018b) Three-dimensional printed PLA scaffold and human gingival stem cell-derived extracellular vesicles: a new tool for bone defect repair. Stem Cell Res Ther 9: 104. DOI: 10.1186/s13287-018-0850-0.

Dlouhy BJ, Awe O, Rao RC, Kirby PA, Hitchon PW (2014) Autograft-derived spinal cord mass following olfactory mucosal cell transplantation in a spinal cord injury patient: case report. J Neurosurg Spine 21: 618622.

Edanami N, Yoshiba K, Shirakashi M, Ibn Belal RS, Yoshiba N, Ohkura N, Tohma A, Takeuchi R, Okiji T, Noiri Y (2020) Impact of remnant healthy pulp and apical tissue on outcomes after simulated regenerative endodontic procedure in rat molars. Sci Rep 10: 20967. DOI: 10.1038/s41598-020-78022-w.

Egusa H, Sonoyama W, Nishimura M, Atsuta I, Akiyama K (2012) Stem cells in dentistry - part I: stem cell sources. J Prosthodont Res 56: 151-165.

Frank J, Richter M, de Rossi C, Lehr CM, Fuhrmann K, Fuhrmann G (2018) Extracellular vesicles protect glucuronidase model enzymes during freeze-drying. Sci Rep 8: 12377. DOI: 10.1038/s41598-018-30786-y.

Fu W, Lei C, Liu S, Cui Y, Wang C, Qian K, Li T, Shen Y, Fan X, Lin F, Ding M, Pan M, Ye X, Yang Y, $\mathrm{Hu} S$ (2019) CAR exosomes derived from effector CAR-T cells have potent antitumour effects and low toxicity. Nat Commun 10: 4355. DOI: 10.1038/s41467019-12321-3.

Galler KM, Brandl FP, Kirchhof S, Widbiller M, Eidt A, Buchalla W, Göpferich A, Schmalz G (2018) Suitability of different natural and synthetic biomaterials for dental pulp tissue engineering. Tissue Eng Part A 24: 234-244. 
Galler KM, Buchalla W, Hiller KA, Federlin M, Eidt A, Schiefersteiner M, Schmalz G (2015) Influence of root canal disinfectants on growth factor release from dentin. J Endod 41: 363-368.

Galler KM, Krastl G, Simon S, Van Gorp G, Meschi N, Vahedi B, Lambrechts P (2016) European Society of Endodontology position statement: revitalization procedures. Int Endod J 49: 717-723.

Giebel B, Kordelas L, Börger V (2017) Clinical potential of mesenchymal stem/stromal cell-derived extracellular vesicles. Stem Cell Investig 4: 84. DOI: 10.21037/sci.2017.09.06.

Gnecchi M, He H, Noiseux N, Liang OD, Zhang L, Morello F, Mu H, Melo LG, Pratt RE, Ingwall JS, Dzau VJ (2006) Evidence supporting paracrine hypothesis for Akt-modified mesenchymal stem cell-mediated cardiac protection and functional improvement. FASEB J 20: 661-669.

Goldstein RH, Reagan MR, Anderson K, Kaplan DL, Rosenblatt M (2010) Human bone marrowderived MSCs can home to orthotopic breast cancer tumors and promote bone metastasis. Cancer Res 70: 10044-10050.

Gurunathan S, Kang MH, Jeyaraj M, Qasim M, Kim JH (2019) Review of the isolation, characterization, biological function, and multifarious therapeutic approaches of exosomes. Cells 8: 307. DOI: 10.3390/ cells8040307.

Hargreaves KM, Giesler T, Henry M, Wang Y (2008) Regeneration potential of the young permanent tooth: what does the future hold. J Endod 34 Suppl 7: S51-S56.

Haynes B (1999) Can it work? Does it work? Is it worth it? The testing of healthcareinterventions is evolving. BMJ 319: 652-653.

He C, Zheng S, Luo Y, Wang B (2018) Exosome theranostics: biology and translational medicine. Theranostics 8: 237-255.

He W, Zhang J, Niu Z, Yu Q, Wang Z, Zhang R, Su L, Fu L, Smith AJ, Cooper PR (2014) Regulatory interplay between NFIC and TGF- $\beta 1$ in apical papilladerived stem cells. J Dent Res 93: 496-501.

Hertig G, Zehnder M, Woloszyk A, Mitsiadis TA, Ivica A, Weber FE (2017) Iodixanol as a contrast agent in a fibrin hydrogel for endodontic applications. Front Physiol 8: 152. DOI: 10.3389/fphys.2017.00152.

Horwitz EM, Prockop DJ, Fitzpatrick LA, Koo WW, Gordon PL, Neel M, Sussman M, Orchard P, Marx JC, Pyeritz RE, Brenner MK (1999) Transplantability and therapeutic effects of bone marrow-derived mesenchymal cells in children with osteogenesis imperfecta. Nat Med 5: 309-313.

Hovatta O (2011) Infectious problems associated with transplantation of cells differentiated from pluripotent stem cells. Semin Immunopathol 33: 627630.

Hu X, Zhong Y, Kong Y, Chen Y, Feng J, Zheng J (2019) Lineage-specific exosomes promote the odontogenic differentiation of human dental pulp stem cells (DPSCs) through TGF $\beta 1 /$ smads signaling pathway via transfer of microRNAs. Stem Cell Res Ther 10: 170. DOI: 10.1186/s13287-019-1278-x.

Huang CC, Narayanan R, Alapati S, Ravindran $S$ (2016) Exosomes as biomimetic tools for stem cell differentiation: applications in dental pulp tissue regeneration. Biomaterials 111: 103-115.

Ibsen SD, Wright J, Lewis JM, Kim S, Ko S-Y, Ong J, Manouchehri S, Vyas A, Akers J, Chen CC (2017) Rapid isolation and detection of exosomes and associated biomarkers from plasma. ACS nano 11: 6641-6651.

Iezzi I, Pagella P, Mattioli-Belmonte M, Mitsiadis TA (2019) The effects of ageing on dental pulp stem cells, the tooth longevity elixir. Eur Cell Mater 37: 175-185.

Iohara K, Imabayashi K, Ishizaka R, Watanabe A, Nabekura J, Ito M, Matsushita K, Nakamura H, Nakashima M (2011) Complete pulp regeneration after pulpectomy by transplantation of CD105+ stem cells with stromal cell-derived factor-1. Tissue Eng Part A 17: 1911-1920.

Ivica A, Ghayor C, Zehnder M, Valdec S, Weber FE (2020) Pulp-derived exosomes in a fibrin-based regenerative root filling material. J Clin Med 9: 491. DOI: 10.3390/jcm9020491.

Ivica A, Zehnder M, Mateos JM, Ghayor C, Weber FE (2019) Biomimetic conditioning of human dentin using citric acid. J Endod 45: 45-50.

Iwaya SI, Ikawa M, Kubota M (2001) Revascularization of an immature permanent tooth with apical periodontitis and sinus tract. Dent Traumatol 17: 185-187.

Jain R, Shah NH, Malick AW, Rhodes CT (1998) Controlled drug delivery by biodegradable poly(ester) devices: different preparative approaches. Drug Dev Ind Pharm 24: 703-727.

Jiang N, Xiang L, He L, Yang G, Zheng J, Wang C, Zhang Y, Wang S, Zhou Y, Sheu TJ, Wu J, Chen K, Coelho PG, Tovar NM, Kim SH, Chen M, Zhou YH, Mao JJ (2017) Exosomes mediate epitheliummesenchyme crosstalk in organ development. ACS Nano 11: 7736-7746.

Kahler B, Mistry S, Moule A, Ringsmuth AK, Case P, Thomson A, Holcombe T (2014) Revascularization outcomes: a prospective analysis of 16 consecutive cases. J Endod 40: 333-338.

Kahler B, Rossi-Fedele G, Chugal N, Lin LM (2017) An evidence-based review of the efficacy of treatment approaches for immature permanent teeth with pulp necrosis. J Endod 43: 1052-1057.

Kalimuthu S, Gangadaran P, Rajendran RL, Zhu L, Oh JM, Lee HW, Gopal A, Baek SH, Jeong SY, Lee SW, Lee J, Ahn BC (2018) A new approach for loading anticancer drugs into mesenchymal stem cellderived exosome mimetics for cancer therapy. Front Pharmacol 9: 1116. DOI: 10.3389/fphar.2018.01116.

Kassebaum NJ, Smith AGC, Bernabé E, Fleming TD, Reynolds AE, Vos T, Murray CJL, Marcenes W, GBD OHC (2017) Global, regional, and national prevalence, incidence, and disability-adjusted life 
years for oral conditions for 195 countries, 19902015: a systematic analysis for the global burden of diseases, injuries, and risk factors. J Dent Res 96: 380-387.

Khojasteh A, Fahimipour F, Jafarian M, Sharifi D, Jahangir S, Khayyatan F, Baghaban Eslaminejad M (2017) Bone engineering in dog mandible: coculturing mesenchymal stem cells with endothelial progenitor cells in a composite scaffold containing vascular endothelial growth factor. J Biomed Mater Res B Appl Biomater 105: 1767-1777.

Kichenbrand C, Velot E, Menu P, Moby V (2019) Dental pulp stem cell-derived conditioned medium: an attractive alternative for regenerative therapy. Tissue Eng Part B Rev 25: 78-88.

Kim JY, Xin X, Moioli EK, Chung J, Lee CH, Chen M, Fu SY, Koch PD, Mao JJ (2010) Regeneration of dental-pulp-like tissue by chemotaxis-induced cell homing. Tissue Eng Part A 16: 3023-3031.

Kling M, Cvek M, Mejare I (1986) Rate and predictability of pulp revascularization in therapeutically reimplanted permanent incisors. Endod Dent Traumatol 2: 83-89.

Koritzinsky EH, Street JM, Star RA, Yuen PS (2017) Quantification of exosomes. J Cell Physiol 232: 15871590.

Kupcova Skalnikova H (2013) Proteomic techniques for characterisation of mesenchymal stem cell secretome. Biochimie 95: 2196-2211.

Lai RC, Arslan F, Lee MM, Sze NS, Choo A, Chen TS, Salto-Tellez M, Timmers L, Lee CN, El Oakley RM, Pasterkamp G, de Kleijn DP, Lim SK (2010) Exosome secreted by MSC reduces myocardial ischemia/ reperfusion injury. Stem Cell Res 4: 214-222.

Langer R, Vacanti JP (1993) Tissue engineering. Science 260: 920-926.

Le Saux S, Aarrass H, Lai-Kee-Him J, Bron P, Armengaud J, Miotello G, Bertrand-Michel J, Dubois E, George S, Faklaris O, Devoisselle JM, Legrand P, Chopineau J, Morille M (2020) Post-production modifications of murine mesenchymal stem cell (mMSC) derived extracellular vesicles (EVs) and impact on their cellular interaction. Biomaterials 231: 119675. DOI: 10.1016/j.biomaterials.2019.119675.

Lui JN, Lim WY, Ricucci D (2020) An immunofluorescence study to analyze wound healing outcomes of regenerative endodontics in an immature premolar with chronic apical abscess. J Endod 46: 627-640.

Mao JJ, Kim SG, Zhou J, Ye L, Cho S, Suzuki T, Fu SY, Yang R, Zhou X (2012) Regenerative endodontics: barriers and strategies for clinical translation. Dent Clin North Am 56: 639-649.

Martin DE, De Almeida JF, Henry MA, Khaing ZZ, Schmidt CE, Teixeira FB, Diogenes A (2014) Concentration-dependent effect of sodium hypochlorite on stem cells of apical papilla survival and differentiation. J Endod 40: 51-55.

Miyajima A, Tanaka M, Itoh T (2014) Stem/ progenitor cells in liver development, homeostasis, regeneration, and reprogramming. Cell Stem Cell 14: 561-574.

Montecalvo A, Larregina AT, Shufesky WJ, Stolz DB, Sullivan ML, Karlsson JM, Baty CJ, Gibson GA, Erdos G, Wang Z, Milosevic J, Tkacheva OA, Divito SJ, Jordan R, Lyons-Weiler J, Watkins SC, Morelli AE (2012) Mechanism of transfer of functional microRNAs between mouse dendritic cells via exosomes. Blood 119: 756-766.

Mulcahy LA, Pink RC, Carter DR (2014) Routes and mechanisms of extracellular vesicle uptake. J Extracell Vesicles 3: . DOI: 10.3402/jev.v3.24641.

Nakamura Y, Miyaki S, Ishitobi H, Matsuyama S, Nakasa T, Kamei N, Akimoto T, Higashi Y, Ochi M (2015) Mesenchymal-stem-cell-derived exosomes accelerate skeletal muscle regeneration. FEBS Lett 589: 1257-1265.

Nakashima M, Iohara K, Murakami M, Nakamura H, Sato Y, Ariji Y, Matsushita K (2017) Pulp regeneration by transplantation of dental pulp stem cells in pulpitis: a pilot clinical study. Stem Cell Res Ther 8: 61. DOI: 10.1186/s13287-017-0506-5.

Nygaard-Ostby B, Hjortdal O (1971) Tissue formation in the root canal following pulp removal. Scand J Dent Res 79: 333-349.

Nygaard-Østby BN (1961) The role of the blood clot in endodontic therapy. an experimental histologic study. Acta Odontol Scand 19: 324-353.

Pegtel DM, Cosmopoulos K, Thorley-Lawson DA, van Eijndhoven MA, Hopmans ES, Lindenberg JL, de Gruijl TD, Würdinger T, Middeldorp JM (2010) Functional delivery of viral miRNAs via exosomes. Proc Natl Acad Sci U S A 107: 6328-6333.

Pelizzo G, Avanzini MA, Mantelli M, Croce S, Maltese A, Vestri E, De Silvestri A, Percivalle E, Calcaterra V (2018) Granulation tissue-derived mesenchymal stromal cells: a potential application for burn wound healing in pediatric patients. J Stem Cells Regen Med 14: 53-58.

Phinney DG, Pittenger MF (2017) Concise review: MSC-derived exosomes for cell-free therapy. Stem Cells 35: 851-858.

Pittenger MF, Mackay AM, Beck SC, Jaiswal RK, Douglas R, Mosca JD, Moorman MA, Simonetti DW, Craig S, Marshak DR (1999) Multilineage potential of adult human mesenchymal stem cells. Science 284: 143-147.

Pivoraitė U, Jarmalavičiūtė A, Tunaitis V, Ramanauskaitė G, Vaitkuvienè A, Kašèta V, Biziulevičienè G, Venalis A, Pivoriūnas A (2015) Exosomes from human dental pulp stem cells suppress carrageenan-induced acute inflammation in mice. Inflammation 38: 1933-1941.

Qing L, Chen H, Tang J, Jia X (2018) Exosomes and their microRNA cargo: new players in peripheral nerve regeneration. Neurorehabil Neural Repair 32: 765-776.

Rebelatto CK, Aguiar AM, Moretão MP, Senegaglia AC, Hansen P, Barchiki F, Oliveira J, Martins J, Kuligovski C, Mansur F, Christofis A, Amaral VF, 
Brofman PS, Goldenberg S, Nakao LS, Correa A (2008) Dissimilar differentiation of mesenchymal stem cells from bone marrow, umbilical cord blood, and adipose tissue. Exp Biol Med (Maywood) 233: 901-913.

Ruparel NB, Teixeira FB, Ferraz CC, Diogenes A (2012) Direct effect of intracanal medicaments on survival of stem cells of the apical papilla. J Endod 38: 1372-1375.

Saoud TM, Zaazou A, Nabil A, Moussa S, Lin LM, Gibbs JL (2014) Clinical and radiographic outcomes of traumatized immature permanent necrotic teeth after revascularization/revitalization therapy. J Endod 40: 1946-1952.

Schrepfer S, Deuse T, Reichenspurner H, Fischbein MP, Robbins RC, Pelletier MP (2007) Stem cell transplantation: the lung barrier. Transplant Proc 39: 573-576.

Sharpe PT (2016) Dental mesenchymal stem cells. Development 143: 2273-2280.

Shi D, Zhang J, Zhou Q, Xin J, Jiang J, Jiang L, Wu T, Li J, Ding W, Li J, Sun S, Li J, Zhou N, Zhang L, Jin L, Hao S, Chen P, Cao H, Li M, Li L, Chen X, Li J (2017) Quantitative evaluation of human bone mesenchymal stem cells rescuing fulminant hepatic failure in pigs. Gut 66: 955-964.

Smyth T, Kullberg M, Malik N, Smith-Jones P, Graner MW, Anchordoquy TJ (2015) Biodistribution and delivery efficiency of unmodified tumor-derived exosomes. J Control Release 199: 145-155.

Song JS, Takimoto K, Jeon M, Vadakekalam J, Ruparel NB, Diogenes A (2017) Decellularized human dental pulp as a scaffold for regenerative endodontics. J Dent Res 96: 640-646.

Swanson WB, Gong T, Zhang Z, Eberle M, Niemann D, Dong R, Rambhia KJ, Ma PX (2020) Controlled release of odontogenic exosomes from a biodegradable vehicle mediates dentinogenesis as a novel biomimetic pulp capping therapy. J Control Release 324: 679-694.

Timmers L, Lim SK, Arslan F, Armstrong JS, Hoefer IE, Doevendans PA, Piek JJ, El Oakley RM, Choo A, Lee CN, Pasterkamp G, de Kleijn DP (2007) Reduction of myocardial infarct size by human mesenchymal stem cell conditioned medium. Stem Cell Res 1: 129-137.

Tkach M, Théry C (2016) Communication by extracellular vesicles: where we are and where we need to go. Cell 164: 1226-1232.

Torabinejad M, Nosrat A, Verma P, Udochukwu O (2017) Regenerative endodontic treatment or mineral trioxide aggregate apical plug in teeth with necrotic pulps and open apices: a systematic review and metaanalysis. J Endod 43: 1806-1820.

Trope M (2010) Treatment of the immature tooth with a non-vital pulp and apical periodontitis. Dent Clin North Am 54: 313-324.
Trubiani O, Marconi GD, Pierdomenico SD, Piattelli A, Diomede F, Pizzicannella J (2019) Human oral stem cells, biomaterials and extracellular vesicles: a promising tool in bone tissue repair. Int J Mol Sci 20: 4987. DOI: 10.3390/ijms20204987.

van Niel G, D'Angelo G, Raposo G (2018) Shedding light on the cell biology of extracellular vesicles. Nat Rev Mol Cell Biol 19: 213-228.

Wang HS, Yang FH, Wang YJ, Pei F, Chen Z, Zhang L (2019) Odontoblastic exosomes attenuate apoptosis in neighboring cells. J Dent Res 98: 1271-1278.

Witwer KW, Théry C (2019) Extracellular vesicles or exosomes? On primacy, precision, and popularity influencing a choice of nomenclature. J Extracell Vesicles 8: 1648167. DOI: 10.1080/20013078.2019.1648167.

Xian X, Gong Q, Li C, Guo B, Jiang H (2018) Exosomes with highly angiogenic potential for possible use in pulp regeneration. J Endod 44: 751758.

Xuan K, Li B, Guo H, Sun W, Kou X, He X, Zhang Y, Sun J, Liu A, Liao L, Liu S, Liu W, Hu C, Shi S, Jin $Y$ (2018) Deciduous autologous tooth stem cells regenerate dental pulp after implantation into injured teeth. Sci Transl Med 10: eaaf3227. DOI: 10.1126/ scitranslmed.aaf3227.

Zhang B, Wang M, Gong A, Zhang X, Wu X, Zhu Y, Shi H, Wu L, Zhu W, Qian H, Xu W (2015) HucMSCexosome mediated-Wnt4 signaling is required for cutaneous wound healing. Stem Cells 33: 2158-2168.

Zhang S, Thiebes AL, Kreimendahl F, Ruetten S, Buhl EM, Wolf M, Jockenhoevel S, Apel C (2020) Extracellular vesicles-loaded fibrin gel supports rapid neovascularization for dental pulp regeneration. Int J Mol Sci 21: 4226. DOI: 10.3390/ijms21124226.

Zhang Y, Liu Y, Liu H, Tang WH (2019) Exosomes: biogenesis, biologic function and clinical potential. Cell Biosci 9: 19. DOI: 10.1186/s13578-019-0282-2.

Zhuang X, Ji L, Jiang H, Liu Y, Liu X, Bi J, Zhao W, Ding Z, Chen X (2020) Exosomes derived from stem cells from the apical papilla promote dentinepulp complex regeneration by inducing specific dentinogenesis. Stem Cells Int 2020: 5816723. DOI: $10.1155 / 2020 / 5816723$.

\section{Web Reference}

1. https://clinicaltrials.gov/ct2/results?cond=\&term $=$ exosomes\&cntry $=\&$ state $=\&$ city $=\&$ dist $=[20-08-2020]$

Editor's note: There were no questions from reviewers for this paper, therefore there is no Discussion with Reviewers section. The Scientific Editor responsible for this paper was Thimios Mitsiadis. 